\title{
Consórcio sorgo e braquiária na entrelinha para produção de grãos, forragem e palhada na entressafra ${ }^{1}$
}

\author{
Alessandro Guerra da Silva', Luiz Eduardo de Moraes $^{3}$, Adalbert Horvathy Neto ${ }^{4}$, \\ Itamar Rosa Teixeira ${ }^{5}$, Gustavo André Simon ${ }^{6}$ \\ http://dx.doi.org/10.1590/0034-737X201461050013
}

\section{RESUMO}

O consórcio tem sido utilizado para produção de grãos e forragem, porém poucos estudos foram realizados com a cultura do sorgo granífero na região Centro-Oeste. Portanto, o objetivo deste trabalho foi o de identificar, na safrinha, o consórcio de sorgo e braquiária, implantadas em duas profundidades de semeadura, que proporcione maiores rendimentos de grãos, massa seca (palhada) e proteína bruta (forragem) com dois cortes nas plantas de braquiária na entressafra. O ensaio foi instalado a campo, em Rio Verde-GO em 05 de março de 2009. Utilizou-se o delineamento experimental de blocos casualizados em esquema fatorial $2 \times 3+1+3$, correspondendo a duas profundidades de semeadura da braquiária (2 e $10 \mathrm{~cm}$ ) e três espécies de braquiária (Brachiaria decumbens (Staf), B. brizantha (Hoschst) cv. Marandu e B. ruziziensis Germain et Evrard) semeadas na entrelinha do sorgo granífero DKB 599, além de quatro tratamentos adicionais sendo um para o monocultivo de sorgo e outros três para cada espécie de braquiária. Os resultados permitiram constatar que o consórcio do sorgo granífero com braquiária na entrelinha apresentou potencial para produção de grãos (exceto da associação com a $B$. decumbens, semeada a $10 \mathrm{~cm}$ de profundidade, e com a $B$. ruziziensis, semeada a $2 \mathrm{~cm}$ ), massa seca e proteína bruta, demonstrando a viabilidade para o sistema de cultivo em plantio direto na região Central do Brasil.

Palavras-chave: Sorghum bicolor L. Moench, rendimento, espécie forrageira, plantio direto, safrinha, sucessão de culturas.

\section{ABSTRACT}

\section{Sorghum intercropped with interrow brachiaria for off-season production of grain, forage and straw}

The intercropping system has been used to produce grain and forage, but few trials have been conducted with sorghum in the Central-West region of Brazil. Therefore, the objective this study was to identify, in the off-season cultivation, the intercropping of sorghum and brachiaria that provides higher grain, dry matter (straw) and crude protein (forage), yieds with two cuttings in off-season brachiaria. The field trial was installed in RioVerde-GO, March 5, 2009. The experiment was arranged in a randomized complete block design in a factorial scheme $2 \times 3+1+3$, corresponding to two sowing depths of brachiaria $(2$ and $10 \mathrm{~cm}$ ) and three species (Brachiaria decumbens,

Recebido para publicação em 06/12/2012 e aprovado em 17/10/2013.

${ }^{1}$ Parte do trabalho de dissertação de mestrado do terceiro autor, apresentado no Programa de Pós-graduação em Produção Vegetal para a obtenção do título de Mestre com apoio financeiro do CNPq para realização do trabalho.

${ }^{2}$ Engenheiro-Agrônomo, Doutor. Programa de Pós-graduação em Produção Vegetal/Faculdade de Agronomia, Universidade de Rio Verde, Campus Universitário Fazenda Fontes do Saber, Caixa Postal 104, 75901-970, Rio Verde, Goiás, Brasil. silvaag @ yahoo.com.br (autor para correspondência).

${ }^{3}$ Engenheiro-Agrônomo. Faculdade de Agronomia, Universidade de Rio Verde, Campus Universitário Fazenda Fontes do Saber, Caixa Postal 104, 75901-970, Rio Verde, Goiás, Brasil. dumoraes86@hotmail.com

${ }^{4}$ Engenheiro-Agrônomo. Universidade de Rio Verde, Campus Universitário Fazenda Fontes do Saber, Caixa Postal 104, 75901-970, Rio Verde, Goiás, Brasil. adalberthorvathy@hotmail.com

${ }_{5}^{5}$ Engenheiro-Agrônomo, Doutor. Departamento de Engenharia Agrícola, Universidade Estadual de Goiás, BR 153, Km 98, Campus Henrique Santillo, 75001-970, Anápolis, Goiás, Brasil. itamarrt@yahoo.com.br

${ }^{6}$ Engenheiro-Agrônomo, Doutor. Programa de Pós-graduação em Produção Vegetal/Faculdade de Agronomia, Universidade de Rio Verde, Campus Universitário Fazenda Fontes do Saber, Caixa Postal 104, 75901-970, Rio Verde, Goiás, Brasil. guasimon@yahoo.com.br 
Brachiaria brizantha cv.Maranduand and B. ruziziensis) sowed in the interrow of DKB 599 grain sorghum. In addition, four treatments corresponding to one sorghum monoculture and three to each brachiaria species were also installed. The intercrop of sorghum with brachiaria in the interrow had potential to produce grain (except the intercropping with the B.decumbens, sown at the depth of $10 \mathrm{~cm}$, and with the B.ruziziensis, at $2 \mathrm{~cm}$ ), dry matter and crude protein, showing the viability of the no-tillage cultivation in the Central-West region of Brazil.

Key words: Sorghum bicolor, yield, forage specie, no-tillage, off-season cultivation, succession crop.

\section{INTRODUÇÃO}

O baixo valor nutritivo das forragens é uma das principais causas da baixa produtividade do rebanho brasileiro. Neste contexto, o sistema de integração lavoura-pecuária permite a produção de grãos e de forragem para ser usada como pastejo, melhorando a disponibilidade de alimentos na entressafra, reduzindo assim a flutuação na oferta de animais para abate ao longo do ano (Melo et al., 2004).

No Brasil Central, muitos produtores têm receio em adotar o sistema de integração lavoura pecuária devido ao não conhecimento do correto estabelecimento e manejo das culturas consorciadas. Quando a taxa de lotação dos animais é manejada de forma racional, as alterações nos atributos físicos do solo são minimizadas (Lanzanova et al., 2007), não causando qualquer dano à cultura cultivada em sucessão ao pastejo (Flores et al., 2007). Associado a isto, o aumento da produção de palha na superfície do solo reduz os efeitos da compactação ocasionada pelo pisoteio dos animais (Lanzanova et al., 2007).

Na região Centro-Oeste, os produtores rurais têm dificuldade de produzir palha na entressafra para a manutenção do sistema plantio direto (Kliemann et al., 2006). Diante disto, há necessidade de se criarem alternativas para manter, por maior tempo possível, a biomassa seca na superfície no solo (Torres et al., 2005). Nesta situação, as culturas de safrinha são fundamentais para a implantação e viabilização do sistema em questão. Neste contexto, a cultura do sorgo é considerada como alternativa para produção de grãos no Centro-Oeste (Heckler, 2002; Silva et al., 2009a), adaptando-se a vários ambientes (Pale et al., 2003; Baumhardt et al., 2005; Dan et al., 2010) que juntamente com a braquiária, proporciona benefícios para o sistema plantio direto (Ikeda et al., 2007).

A viabilidade do cultivo de Brachiaria brizantha cv. Marandu em consórcio com sorgo e outros cereais é demonstrada em trabalhos de pesquisa (Portes et al., 2000; Melo et al., 2004). Além disto, o manejo de ervas daninhas a partir da produção da palhada do sorgo (Souza et al., 1999) e Brachiaria brizantha (Braz et al., 2006) é facilitado, o que proporciona menor infestação para a cultura em sucessão. Como o consórcio de braquiárias com sorgo é pouco explorado na safrinha, há necessidade de maiores informações, sobretudo no que diz respeito às recomen- dações de implantação e exploração da produção de biomassa na entressafra.

Assim, o objetivo deste trabalho foi verificar, na safrinha, o potencial de produção de grãos, massa seca e proteína bruta do consórcio entre sorgo granífero e três espécies de braquiária, implantadas em duas profundidades de semeadura, comparativamente ao monocultivo das quatro espécies em estudo.

\section{MATERIAL E MÉTODOS}

O ensaio foi conduzido a campo, com coordenadas de $17^{\circ} 47^{\prime} 24,5^{\prime \prime} \mathrm{S} ; 50^{\circ} 57^{\prime} 41,7^{\prime \prime} \mathrm{W}$ e $769 \mathrm{~m}$ de altitude, no município de Rio Verde-GO, na safrinha de 2009, em solo classificado como Latossolo Vermelho distrófico, cultivado no sistema plantio direto com soja como cultura de verão. Os resultados da análise química da amostra de solo do local de realização do ensaio foram: $\mathrm{pH}$ em $\mathrm{CaCl}_{2}$ : 4,8; $\mathrm{Ca}, \mathrm{K}, \mathrm{Mg}, \mathrm{Al}, \mathrm{H}+\mathrm{Al}$, CTC e SB: 1,03; 0,$32 ; 0,66 ; 0,05 ; 4,3 ; 6,3$ e 2,01 em cmol $\mathrm{dm}^{-3}$, respectivamente; P: 2,29 $\mathrm{mg} \mathrm{dm}^{-3}$; saturação de bases e de alumínio: 31,94 e 2,43\%, respectivamente; argila, silte e areia: 590; 130 e $280 \mathrm{~g} \mathrm{~kg}^{-1}$, respectivamente. As variações mensais de temperatura média do ar e precipitação durante a condução do ensaio estão dispostas na Figura 1.

O delineamento experimental adotado foi o de blocos casualizados (DBC), em esquema fatorial $2 \times 3$, acrescido de quatro tratamentos adicionais, todos implantados com quatro repetições. O primeiro fator correspondeu a duas profundidades de semeadura da braquiária $(2$ e $10 \mathrm{~cm})$ e o segundo pelas três espécies de braquiária (Brachiaria decumbens, B. brizantha cv. Marandu e B. ruziziensis). Os tratamentos adicionais, instalados na mesma sequência do consórcio, também em DBC, referem-se aos monocultivos do sorgo granífero e das três espécies de braquiária. Estes tinham como objetivo a comparação da eficiência do consórcio em relação aos monocultivos das espécies consorciadas. O sorgo, em ambos sistemas de cultivo, foi semeado a $2 \mathrm{~cm}$ de profundidade, sendo o mesmo feito para a braquiária em monocultivo.

No consórcio, foram realizados dois cortes nas plantas de braquiária: o primeiro a $30 \mathrm{~cm}$ acima do nível do solo aos 52 dias após a colheita do sorgo e o segundo 
após a rebrota das plantas, rente ao solo aos 46 dias após o primeiro corte. No monocultivo, as braquiárias foram cortadas uma única vez, rente ao solo, aos 98 dias após a colheita do sorgo.

O sorgo granífero utilizado foi o DKB 599 (caracterizado por ser precoce, de grãos vermelhos e sem tanino). As parcelas foram constituídas de sete linhas de sorgo, com 5,0 m de comprimento, espaçadas $0,45 \mathrm{~m}$ entre si, sendo a área útil obtida desconsiderando-se as duas linhas laterais e eliminando $0,5 \mathrm{~m}$ de cada extremidade $\left(5,4 \mathrm{~m}^{2}\right)$.

Uma semana antes da implantação do ensaio foi realizada, de forma mecanizada, a dessecação das ervas daninhas empregando o equivalente a 1440 g e.a. ha ${ }^{-1}$ de glyphosate e 433,5 g i.a. ha-1 de 2,4-D, utilizando-se 150 $\mathrm{L} \mathrm{ha}^{-1}$ de volume de calda. A semeadura de ambas as culturas foi realizada em cinco de março. Para a implantação das braquiárias levou-se em consideração o valor cultural (VC) das sementes (B. brizantha e $B$. ruziziensis: VC de $75,6 \%, 3,2 \mathrm{~kg} \mathrm{ha}^{-1} ; B$. decumbens: VC de $\left.34,1 \%, 7,0 \mathrm{~kg} \mathrm{ha}^{-1}\right)$, empregando a seguinte expressão $\left(240 \mathrm{VC}^{-1}\right)$ para obtenção da quantidade equivalente de sementes em $\mathrm{kg} \mathrm{ha}^{-1}$.

Um dia antes da semeadura, demarcou-se, com emprego de uma semeadora, os sulcos de semeadura do sorgo com espaçamento entrelinhas de $45 \mathrm{~cm}$. Nessa ocasião, realizou-se a aplicação de $300 \mathrm{~kg} \mathrm{ha}^{-1}$ do fertilizante 02-20-18. No dia da semeadura, foram feitos os sulcos de semeadura da braquiária nas entrelinhas do sorgo nas profundidades de 2 e $10 \mathrm{~cm}$, com uso de enxadas. Tanto o sorgo com a braquiária foram implantados manualmente, sendo o sorgo semeado a $2 \mathrm{~cm}$ de profundidade e as braquiárias a 2 e a $10 \mathrm{~cm}$, conforme tratamentos descritos anteriormente. Em monocultivo, ambas espécies foram semeadas a $2 \mathrm{~cm}$ de profundidade. Aos
25 dias após a emergência (DAE), foi realizado o desbaste do sorgo deixando-se população equivalente a 180 mil plantas ha ${ }^{-1}$ e logo em seguida realizou-se a aplicação de $100 \mathrm{~kg} \mathrm{ha}^{-1}$ de $\mathrm{N}$ na forma de ureia ao lado da linha de semeadura do sorgo.

O controle das plantas daninhas em pós-emergência foi realizado por meio de duas capinas manuais realizadas aos 15 e 30 DAE, visando eliminar qualquer espécie de planta diferente a de sorgo e braquiária. Na fase de emborrachamento do sorgo (42 DAE) aplicou-se, de forma mecanizada, $50 \mathrm{~g} \mathrm{ha}^{-1}$ de cipermetrina visando o controle de Spodoptera frugiperda, utilizando-se volume de calda de $150 \mathrm{~L} \mathrm{ha}^{-1}$.

A colheita do sorgo foi realizada aos 130 DAE, sendo avaliadas, na área útil das parcelas, as seguintes características relativas a essa espécie: rendimento de grãos (colheita das panículas, com posterior debulha e pesagem dos grãos, com correção da umidade para 13\%); peso de 1.000 grãos (determinação do peso de mil grãos, escolhidos aleatoriamente na amostra de rendimento de grãos, com correção da umidade para 13\%); altura de plantas (medição do colo até a extremidade da panícula em cinco plantas escolhidas aleatoriamente); índice de perfilhamento (contagem do número de perfilhos em cinco plantas escolhidas aleatoriamente); estande final (contagem do número total de plantas colhidas); e acamamento de plantas (porcentagem do número de plantas acamadas).

Uma vez colhido o sorgo, as braquiárias permaneceram no campo sendo avaliados, no momento do segundo corte (98 dias após a colheita do sorgo), a altura das plantas (medição aleatória em cinco plantas do colo até a extremidade da última folha completamente expandida) e o índice de perfilhamento (contagem do número de perfilhos em cinco plantas).

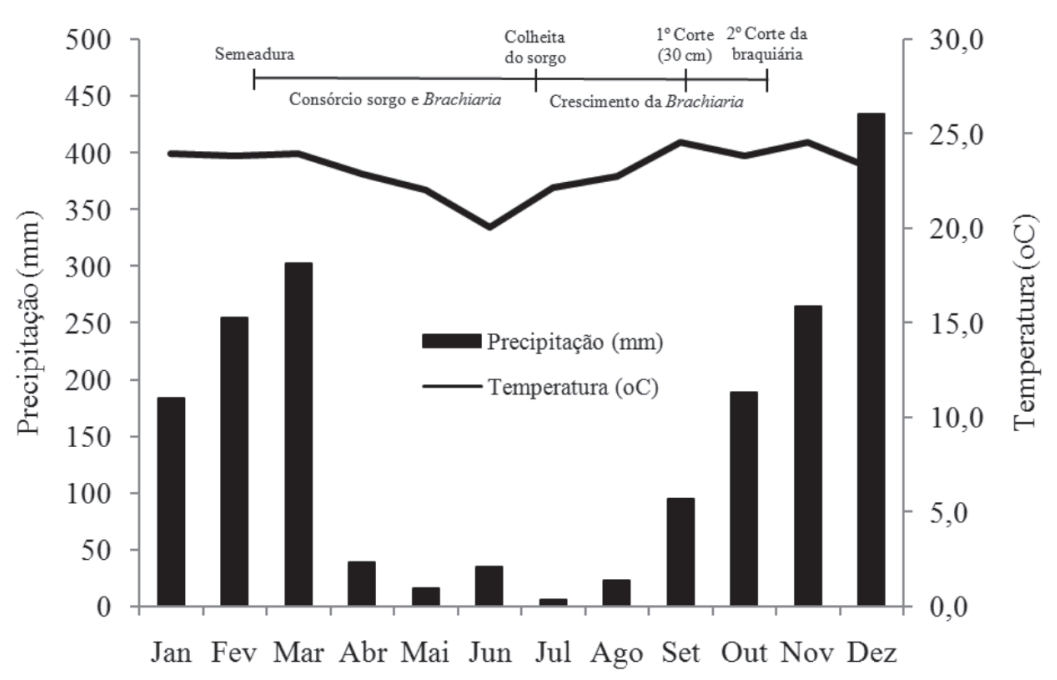

Figura 1. Variação mensal da temperatura média do ar e precipitação pluvial de janeiro a dezembro de 2009. 
Para avaliar o consórcio, nos cortes das braquiárias (52 e 46 dias após a colheita do sorgo) foram quantificados e posteriormente somados os valores de rendimento de massa seca total (coleta da biomassa do sorgo e braquiária, em $1 \mathrm{~m}^{2}$, por meio da utilização de um quadrado de ferro de dimensões de 1,0 x 1,0 m. Essas amostras foram acondicionadas em sacos de papel, separadas por espécie, e levadas para estufa a $65^{\circ} \mathrm{C}$ para secagem, determinando-se posteriormente o peso de matéria seca e, em seguida, o rendimento de massa seca total, em $\mathrm{kg} \mathrm{ha}^{-1}$ ) e o rendimento de proteína bruta total (as amostras de massa seca foram moídas em moinho do tipo Willey, de peneira de $1 \mathrm{~mm}$ de diâmetro, determinando, posteriormente, o teor de $\mathrm{N}$ pelo método microKjeldahl; os resultados obtidos foram multiplicados por 6,25 para se obter o teor de proteína bruta (Malavolta et al., 1997); na sequência efetuou-se o produto do rendimento de massa seca pelo teor de proteína bruta e os resultados de cada espécie foram somados para se obter o rendimento de proteína bruta total, em $\mathrm{kg} \mathrm{ha}^{-1}$ ).

Para cada espécie, quantificou-se ainda a relação C/ $\mathrm{N}$ no momento do segundo corte das plantas de braquiária (o C orgânico foi determinado pela queima das amostras em mufla à $550^{\circ} \mathrm{C}$ (Embrapa, 1997) e o N pelo método microKjeldahl, como relatado anteriormente, obtendo-se em seguida a relação $\mathrm{C} / \mathrm{N}$ de cada espécie). Foi realizada também a quantificação da cobertura do solo por ocasião da colheita do sorgo (determinada em dois pontos escolhidos aleatoriamente na área útil da parcela, com utilização de um quadrado de ferro de $0,5 \times 0,5$ $\mathrm{m}$, contendo uma linha com dez pontos separados e equidistantes, quantificando-se a porcentagem de cobertura na superfície do solo, em porcentagem, quando esses pontos coincidiam com a presença de cobertura vegetal). E por fim foi calculado o índice de equivalência de área, no qual foi obtido pelo somatório da relação do rendimento de grãos de sorgo (consórcio/monocultivo) e de massa seca ([sorgo+braquiária em consórcio]/ monocultivo de braquiária).

Os resultados obtidos foram submetidos a análise de variância utilizando os programas estatísticos SISVAR e Genes. Para avaliar o efeito dos fatores Braquiária e Profundidade de semeadura empregou-se o teste de Tukey a $5 \%$ de probabilidade para comparação de médias quando constatada significância. Para comparar o consórcio e o monocultivo (fatorial $\mathrm{x}$ tratamentos adicionais), empregaram-se contrastes e o teste de Dunnett a 5\% de probabilidade. Para o índice de equivalência de área, no qual o valor obtido envolve informações oriundas do consórcio e monocultivo, empregou-se o esquema fatorial simples $2 \times 3$, referente às duas profundidades de semeadura e às três espécies de braquiária.

\section{RESULTADOS E DISCUSSÃO}

\section{Cultura do sorgo}

Os resultados da análise de variância para a cultura do sorgo permitiram constatar significância para as fontes de variação "Profundidade de semeadura x Braquiária" e "Consórcio x Monocultivo" para rendimento de grãos e de "Braquiária" e "Profundidade de semeadura $\mathrm{x}$ Braquiária" para o peso de mil grãos (Tabela 1). Para as demais variáveis, constatou-se ausência de significância para as fontes de variação testadas.

Para cada espécie de braquiária e em cada profundidade de semeadura, pode-se constatar que quando o sorgo foi consorciado com a B. decumbens, semeada a $10 \mathrm{~cm}$, e com a $B$. ruziziensis, semeada a $2 \mathrm{~cm}$, houve reduções no rendimento de grãos do sorgo (Tabela 2). Por outro lado, a profundidade de semeadura da $B$. brizantha não influenciou o rendimento de grãos do sorgo. A menor competição desta espécie, quando semeada a $10 \mathrm{~cm}$ nas entrelinhas do sorgo, se deve ao fato do aumento da profundidade de semeadura ter retardado seu crescimento inicial, associado ao fato do consórcio ser realizado nas entrelinhas, minimizando os efeitos da competição, o mesmo sendo verificado para a $B$. decumbens semeada a $10 \mathrm{~cm}$. Além disso, a $B$. ruziziensis apresenta crescimento inicial prostrado, permitindo que as plantas de sorgo se desenvolvessem sem a interferência na fase inicial de desenvolvimento.

A análise do rendimento de grãos indicou que o consórcio de braquiária na entrelinha de sorgo granífero mostrou-se vantajoso, pois na maior parte das combinações de ambas as culturas, não foram constatadas diferenças significativas entre os valores obtidos em consórcio e monocultivo (Tabela 2). As exceções ocorreram para o consórcio da $B$. decumbens, semeada a $10 \mathrm{~cm}$, e da $B$. ruziziensis, semeada a $2 \mathrm{~cm}$, cujos resultados foram inferiores em relação ao monocultivo de sorgo. Como não foi usada nenhuma técnica de manejo para suprimir o crescimento inicial da braquiária, houve uma maior competição com as plantas de sorgo, ocasionando desta forma menor rendimento de grãos. Apesar dos resultados de pesquisa serem escassos no que se refere ao rendimento do sorgo na safrinha, os valores obtidos no consórcio e no monocultivo são semelhantes aos de Silva et al. (2009a) e inferiores aos de Heckler (2002) com o cultivo do cereal em sucessão a soja na região Centro-Oeste.

$\mathrm{Na}$ avaliação do peso de mil grãos, foram constatadas reduções nos valores quando as plantas foram cultivadas em consórcio com $B$. brizantha, semeada a $2 \mathrm{~cm}$ de profundidade, e da B. decumbens a $10 \mathrm{~cm}$ (Tabela 2). Esse fato pode ser atribuído a maior competição das plantas de braquiária com as de sorgo na fase vegetativa desta espécie, fazendo com que houvesse menor produção de 
fotoassimilados, e consequentemente menor quantidade para serem transportados aos grãos após a fase de floração. Ressalta-se que o menor rendimento de grãos do sorgo obtido com o consórcio com a $B$. decumbens semeada a $10 \mathrm{~cm}$ de profundidade, em relação a semeadura a $2 \mathrm{~cm}$, deve-se ao maior aproveitamento da umidade do solo pelas plantas de braquiária na fase inicial de desenvolvimento quando implantadas em maior profundidade. Isso favoreceu a emergência das plântulas, visto que a espécie em questão tinha menor valor cultural de sementes em relação às demais. Desta forma houve maior competição com as plantas de sorgo, o que ocasionou menor rendimento de grãos. Na avaliação da semeadura a $2 \mathrm{~cm}$ de profundidade, não houve diferenças entre as espécies, e a $10 \mathrm{~cm}$ a $B$. brizantha foi a que exerceu menor interferência no peso de mil grãos comparativamente às demais espécies.

Os valores do índice de perfilhamento, altura de plantas, estande, acamamento de plantas e relação $\mathrm{C} / \mathrm{N}$ da cultura do sorgo em consórcio não diferiram dos observados em monocultivo de sorgo (Tabela 2). Devido ao consórcio ter sido realizado na entrelinha, houve maior incidência de luz no terço basal das plantas de sorgo, não suprimindo, desta forma, o perfilhamento da cultura (Taiz \& Zeiger, 2010). Além disso o consórcio com braquiária na entrelinha proporcionou menor competição com o sorgo, não influenciando nas variáveis analisadas. É oportuno destacar que os valores obtidos da relação $\mathrm{C} / \mathrm{N}$ do sorgo são semelhantes aos de Silva et al. (2009b) e superiores aos de Calvo et al. (2010) de 100 e 55, respectivamente, para o sorgo BRS 800 (corte e pastejo). Maiores valores da relação $\mathrm{C} / \mathrm{N}$ tornam-se vantajosos para aumentar o tempo de permanência da palhada na superfície do solo (Kliemann et al., 2006).

\section{Cultura da braquiária}

$\mathrm{Na}$ avaliação das características das braquiárias, foram constatadas diferenças significativas para a altura de plantas (Profundidade de semeadura, Braquiária e Monocultivo), Índice de perfilhamento da braquiária (Monocultivo e Consórcio x Monocultivo) e relação C/N (Braquiária e Monocultivo) (Tabela 1).

Em geral pode-se constatar que a semeadura na entrelinha a $10 \mathrm{~cm}$ possibilitou maior desenvolvimento das plantas de braquiária, sendo a maior altura constatada com a B. decumbens, tanto no consórcio como no monocultivo (Tabela 3). O maior porte é justificado pelo melhor desempenho desta espécie quando cultivada em solos de menor fertilidade (Vilela et al., 1998), como o solo usado para realização do ensaio.

$\mathrm{O}$ índice de perfilhamento das plantas de braquiária também foi influenciado pelo ambiente do consórcio. $\mathrm{O}$ sombreamento provocado pelas plantas de sorgo ocasio- 
naram reduções significativas no perfilhamento de $B$. brizantha e $B$. ruziziensis, independentemente da profundidade de semeadura (médias inferiores aos respectivos monocultivos) (Tabela 3). A redução do perfilhamento da braquiária pode ser atribuída à supressão na emissão dos perfilhos nas gemas axilares (Matthew et al., 2000; Taiz \& Zeiger, 2010) durante o desenvolvimento da cultura do sorgo. Em monocultivo observouse que a $B$. ruziziensis foi a de maior capacidade de perfilhamento, seguida da B. brizantha e B. ruziziensis.
A relação $\mathrm{C} / \mathrm{N}$ da $B$. decumbens no consórcio foi superior às demais, sendo o menor valor obtido com a $B$. ruziziensis (Tabela 3 ). No monocultivo a $B$. decumbens apresentou também valores superiores em relação à $B$. ruziziensis. Os resultados obtidos no monocultivo são superiores aos de outros trabalhos de pesquisa com $B$. brizantha cv. Marandu (Torres et al., 2005) e Xaraés (Rodrigues et al., 2007), B. decumbens (Souza et al., 1999) e inferiores ao da B. ruziziensis (Menezes \& Leandro, 2004).

Tabela 2. Valores médios de rendimento (REND) e peso de mil grãos (P1000G), índice de perfilhamento (IPS), altura (APS), estande (EST), acamamento (ACAM) e relação $\mathrm{C} / \mathrm{N}(\mathrm{CN} /(\mathrm{S}))$ da cultura do sorgo consorciado na entrelinha com $B$. brizantha $(B b), B$. decumbens $(B d)$ e $B$. ruziziensis $(B r)$ semeadas a 2 e $10 \mathrm{~cm}$ de profundidade na safrinha ${ }^{11}$

\begin{tabular}{|c|c|c|c|c|c|}
\hline Consórcio & $B b$ & & $B d$ & $\mathrm{Br}$ & Média \\
\hline \multicolumn{6}{|c|}{$\operatorname{REND}\left(\mathrm{kg} \mathrm{ha}^{-1}\right)$} \\
\hline $2 \mathrm{~cm}$ & $2.631 \mathrm{Aa}$ & & $2.752 \mathrm{Aa}$ & $1.186 \mathrm{Bb}^{*}$ & 2.190 \\
\hline $10 \mathrm{~cm}$ & $2.057 \mathrm{Aa}$ & & $1.676 \mathrm{Ba}^{*}$ & $2.390 \mathrm{Aa}$ & 2.041 \\
\hline Média & 2.344 & & 2.214 & 1.788 & \\
\hline Monocultivo & & & 2.917 & & \\
\hline \multicolumn{6}{|c|}{ P1000G (g) } \\
\hline $2 \mathrm{~cm}$ & $15,6 \mathrm{Ba}$ & & $16,1 \mathrm{Aa}$ & $15,0 \mathrm{Aa}$ & 15,6 \\
\hline $10 \mathrm{~cm}$ & $17,9 \mathrm{Aa}$ & & $13,8 \mathrm{Bc}$ & $16,2 \mathrm{Ab}$ & 16,0 \\
\hline Média & $16,8 \mathrm{a}$ & & $15,0 \mathrm{~b}$ & $15,6 \mathrm{~b}$ & \\
\hline \multirow[t]{2}{*}{ Monocultivo } & \multicolumn{5}{|c|}{16,1} \\
\hline & IPS (\%) & APS (m) & EST $(x$ 10.000) & $\operatorname{ACAM}(\%)$ & $\mathrm{C} / \mathrm{N}(\mathrm{S})$ \\
\hline Consórcio & 3,70 & 1,14 & 13,26 & 0,9 & 106 \\
\hline Monocultivo & 3,50 & 1,15 & 12,28 & 1,3 & 100 \\
\hline
\end{tabular}

* Média difere significativamente pelo teste de Dunnett a $5 \%$ de probabilidade em relação ao monocultivo de sorgo.

${ }^{/ 1}$ Médias seguidas pela mesma letra maiúscula na coluna e minúscula na linha não diferem entre si pelo teste de Tukey a 5\% de probabilidade.

Tabela 3. Valores médios de altura (APB), índice de perfilhamento (IPB) e relação $\mathrm{C} / \mathrm{N}(\mathrm{C} / \mathrm{N}(\mathrm{B}))$ de plantas de braquiária do consórcio na entrelinha de sorgo com B. brizantha $(B b)$, B. decumbens $(B d)$ e B. ruziziensis $(B r)$ semeadas a 2 e $10 \mathrm{~cm}$ de profundidade na safrinha ${ }^{\prime 1}$

\begin{tabular}{|c|c|c|c|c|}
\hline Consórcio & $B \boldsymbol{b}$ & $B d$ & $B r$ & Média \\
\hline \multicolumn{5}{|c|}{ APB $(\mathrm{cm})$} \\
\hline $2 \mathrm{~cm}$ & 0,27 & 0,35 & 0,33 & $0,32 \mathrm{~b}$ \\
\hline $10 \mathrm{~cm}$ & 0,34 & 0,43 & 0,35 & $0,38 \mathrm{a}$ \\
\hline Média & $0,31 \mathrm{~b}$ & $0,39 \mathrm{a}$ & $0,34 \mathrm{~b}$ & \\
\hline Monocultivo & $0,25 \mathrm{~b}$ & $0,67 \mathrm{a}$ & $0,22 b$ & \\
\hline \multicolumn{5}{|c|}{ IPB $\left(\mathrm{n}^{\circ}\right.$ de perfilhos planta $\left.^{-1}\right)$} \\
\hline $2 \mathrm{~cm}$ & $10,75 *$ & 12,50 & $15,58 *$ & 12,94 \\
\hline $10 \mathrm{~cm}$ & $14,58 *$ & 14,42 & $15,25 *$ & 14,75 \\
\hline Média & 12,67 & 13,46 & 15,42 & \\
\hline Monocultivo & $24,83 \mathrm{~b}$ & $16,58 \mathrm{c}$ & $32,08 \mathrm{a}$ & \\
\hline \multicolumn{5}{|c|}{$\mathrm{C} / \mathrm{N}(\mathrm{B})$} \\
\hline $2 \mathrm{~cm}$ & 37,58 & 59,98 & 28,38 & 41,98 \\
\hline $10 \mathrm{~cm}$ & 35,07 & 67,45 & 25,10 & 42,54 \\
\hline Média & $36,32 \mathrm{~b}$ & 63,72 a & $26,74 \mathrm{c}$ & \\
\hline Monocultivo & $42,67 \mathrm{a}$ & $48,20 \mathrm{a}$ & $34,34 \mathrm{~b}$ & \\
\hline
\end{tabular}

* Média difere significativamente pelo teste de Dunnett a 5\% de probabilidade em relação ao monocultivo de braquiária.

${ }^{/ 1}$ Médias seguidas pela mesma letra maiúscula na coluna e minúscula na linha não diferem entre si pelo teste de Tukey a 5\% de probabilidade. 
A maior relação $\mathrm{C} / \mathrm{N}$ apresentada pela $B$. decumbens torna-se vantajosa quando se objetiva manter, por mais tempo, a palhada na superfície do solo. Ressalta-se que a determinação dessa variável foi realizada aos 98 dias após a colheita do sorgo, sendo que as plantas de braquiária apresentavam 36 dias de idade após o primeiro corte. É oportuno ressaltar que o maior tempo de permanência da palhada na superfície do solo na fase inicial de desenvolvimento da soja, a qual é implantada no início do período chuvoso nos cerrados, propicia proteção do solo contra erosão (Kliemann et al., 2006) e a supressão de ervas daninhas. Nos primeiros dias de desenvolvimento a cultura da soja não tem a capacidade de proporcionar uma cobertura efetiva do solo e a presença de biomassa seca sobre o solo estaria viabilizando, assim, o sistema de plantio direto na região dos cerrados (Menezes \& Leandro, 2004; Kliemann et al., 2006).

\section{Sorgo e braquiária}

$\mathrm{Na}$ avaliação da produção de biomassa de sorgo e braquiária foram constatadas significâncias para as fontes de variação "Monocultivo" e "Consórcio x Monocultivo" para o rendimento de massa seca, proteína bruta total e cobertura do solo, além do efeito de "Braquiária" e interação "Profundidade de semeadura x Braquiária" para rendimento de proteína bruta total e índice de equivalência de área (Tabela 1).

O consórcio na entrelinha, efetuando dois cortes nas plantas de braquiária, mostrou-se como prática vantajosa para produção de massa seca na entressafra, sendo os valores superiores aos do monocultivo do sorgo (Tabela 4). Por outro lado, não houve diferenças em relação aos respectivos monocultivos de braquiária, mesmo explorando a rebrota das plantas (Portes et al., 2000). É oportuno destacar que os valores do consórcio foram oriundos de dois cortes das plantas de braquiária (52 e 98 dias após a colheita do sorgo, Figura 1), possibilitando o uso para pastejo na entressafra. Neste período, as pastagens do cerrado encontram-se debilitadas para pastejo do gado. A rebrota das plantas de braquiária possibilitou um segundo corte, o qual poderá ser usado para estabelecimento de uma nova pastagem ou para produção de massa seca para implantação da cultura da soja. Assim o consórcio de culturas na safrinha possibilita a obtenção de três culturas com quatro diferentes usos em uma única safra agrícola, em condições de sequeiro (soja verão, sorgo

Tabela 4. Valores médios de rendimentos de massa seca total (RMST) e de proteína bruta total (RPBT), cobertura do solo (CS) e índice de equivalência de área (IEA) do consórcio na entrelinha de sorgo com B. brizantha $(B b), B$. decumbens $(B d)$ e $B$. ruziziensis $(B r)$ semeadas a 2 e $10 \mathrm{~cm}$ de profundidade na safrinha ${ }^{11}$

\begin{tabular}{|c|c|c|c|c|}
\hline Consórcio & $B b$ & $B d$ & $B r$ & Média \\
\hline \multicolumn{5}{|c|}{$\operatorname{RMST}\left(\mathrm{kg} \mathrm{ha}^{-1}\right)$} \\
\hline $2 \mathrm{~cm}$ & $2.371 * 1$ & $2.423 * 1$ & $1.742 * 1$ & 2.179 \\
\hline $10 \mathrm{~cm}$ & $1.718 * 1$ & $1.961 * 1$ & $2.001 * 1$ & 1.893 \\
\hline Média & 2.045 & 2.192 & 1.872 & \\
\hline \multirow[t]{2}{*}{ Monocultivo } & $B b$ & $B d$ & $\mathrm{Br}$ & Sorgo \\
\hline & $1.668 \mathrm{a}$ & $1.736 \mathrm{a}$ & $1.965 \mathrm{a}$ & $625 \mathrm{~b}$ \\
\hline \multicolumn{5}{|c|}{ RPBT (kg ha-1) } \\
\hline $2 \mathrm{~cm}$ & $165 \mathrm{Aa}^{* 1}$ & $133 \mathrm{Aa}^{* 1,2}$ & $156 \mathrm{Ba}^{* 1,2}$ & 152 \\
\hline $10 \mathrm{~cm}$ & $153 \mathrm{Ab}^{* 1}$ & $113 \mathrm{Ac}^{* 1}$ & $192 \mathrm{Aa}^{* 1}$ & 152 \\
\hline Média & $159 a$ & $123 \mathrm{~b}$ & $174 \mathrm{a}$ & \\
\hline Monocultivo & $B b$ & $B d$ & $B r$ & Sorgo \\
\hline Monocultivo & $135 b$ & $93 \mathrm{c}$ & $202 \mathrm{a}$ & $13 \mathrm{~d}$ \\
\hline \multicolumn{5}{|c|}{ CS (\%) } \\
\hline $2 \mathrm{~cm}$ & $51,2 * 2$ & $56,2 * 1,2$ & 55,0 & 54,1 \\
\hline $10 \mathrm{~cm}$ & $51,2 * 2$ & $58,7 * 1,2$ & $50,7 * 2$ & 53,5 \\
\hline Média & 51,2 & 57,5 & 52,8 & \\
\hline Monocultivo & $B b$ & $B d$ & $B r$ & Média \\
\hline Monocultivo & $72,0 \mathrm{ab}$ & $83,7 \mathrm{a}$ & $65,7 \mathrm{~b}$ & $42,5 \mathrm{c}$ \\
\hline \multicolumn{5}{|c|}{ IEA } \\
\hline $2 \mathrm{~cm}$ & 1,85 & 1,83 & 1,03 & 1,57 \\
\hline $10 \mathrm{~cm}$ & 1,44 & 1,39 & 1,47 & 1,43 \\
\hline Média & 1,65 & 1,61 & 1,25 & \\
\hline
\end{tabular}

*1 $*^{2}$ : Média difere significativamente pelo teste de Dunnett a 5\% de probabilidade em relação ao monocultivo de sorgo e braquiária respectivamente.

${ }^{/ 1}$ Médias seguidas pela mesma letra maiúscula na coluna e minúscula na linha não diferem entre si pelo teste de Tukey a 5\% de probabilidade. 
safrinha e massa seca de sorgo e braquiária para pastejo e produção de palhada na entressafra).

No monocultivo observou-se desempenho superior das braquiárias em relação ao sorgo para rendimento de massa seca, as quais não diferiram entre si (Tabela 4). Portanto, os resultados comprovam o potencial de produção de biomassa da forrageira e a adaptação a solos de cerrado (Euclides et al, 2008), principalmente da $B$. decumbens em solos de menor fertilidade (Vilela et al., 1998) superando os resultados de outros trabalhos de pesquisa (Paciullo et al., 2003; Machado \& Assis, 2010).

Para a proteína bruta total, o consórcio da $B$. ruziziensis, semeada a $10 \mathrm{~cm}$, proporcionou rendimento superior em relação à profundidade de $2 \mathrm{~cm}$, não havendo diferenças para as demais espécies (Tabela 4). Em uma mesma profundidade, maiores valores foram observados para a $B$. ruziziensis semeada a $10 \mathrm{~cm}$, superando as demais.

A vantagem do consórcio pode ser comprovada pela contribuição significativa de proteína bruta pela braquiária em todos tratamentos quando comparados com o monocultivo do sorgo (Tabela 4). O consórcio com a $B$. decumbens, semeada a $2 \mathrm{~cm}$, foi o único que superou o monocultivo da forrageira. Para as demais combinações do consórcio, exceto para a B. ruziziensis semeada a $2 \mathrm{~cm}$, não foram observadas diferenças significativas em relação aos respectivos monocultivos de braquiária. Neste sistema o maior valor de proteína bruta foi obtido com a $B$. ruziziensis, seguida da $B$. brizantha, $B$. decumbens e pelo sorgo, comprovando o potencial das braquiárias para uso na forma de forragem (Machado \& Assis, 2010).

A avaliação da cobertura do solo permitiu constatar maiores valores no monocultivo em relação ao consórcio, destacando-se os resultados da $B$. decumbens cujo valor superou o da B. ruziziensis (Tabela 4). Os menores valores obtidos no consórcio podem ser atribuídos ao sombreamento do sorgo nas plantas de braquiária, suprimindo o crescimento da forrageira. Mas quando se compara com o monocultivo de sorgo, houve maior cobertura do solo pela produção de massa seca da B. decumbens, independentemente da profundidade de semeadura. Ressalta-se que esta avaliação foi realizada na colheita do sorgo e no segundo corte das plantas de braquiária, toda a superfície do solo estava coberta pela biomassa das plantas, o que não ocorreu com o monocultivo do sorgo. Isto comprova o incremento de cobertura vegetal pela braquiária (Timossi et al., 2007; Machado \& Assis, 2010) favorecendo assim a conservação do solo (Silva et al., 2007).

O índice de equivalência de área permitiu comprovar novamente a eficiência do consórcio para produção de grãos e massa seca em relação aos respectivos monoculti- vos das espécies consorciadas (Tabela 4). Nesse caso, todas as combinações apresentaram valores superiores a um, com destaque para as associações que apresentaram maiores rendimentos de grãos. Outros trabalhos de pesquisa têm comprovado vantagens do consórcio de sorgo para produção de forragem (Silva et al., 2003; Rezende et al., 2004).

No consórcio a produção de proteína bruta foi obtida com dois cortes da braquiária. Caso o produtor opte, a forragem produzida pode ser empregada para dois pastejos na entressafra. Outra opção seria o cultivo de soja na próxima safra. Neste caso, há a necessidade de se interromper o pastejo para possibilitar o crescimento e o aumento da biomassa das plantas de braquiária, que futuramente será dessecada para implantação da cultura de verão.

A realização do corte da braquiária aos 52 dias após a colheita do sorgo possibilitou a rebrota das plantas, o que permitiu uma segunda produção de biomassa. Portanto, a partir dos resultados obtidos, comprovou-se a viabilidade do consórcio na entrelinha de sorgo granífero com braquiária visando produção de grãos, forragem e palhada na entressafra. Esta modalidade de cultivo permite ao produtor aumentar os ganhos com a atividade agrícola explorando, de forma racional, o sistema de integração lavoura-pecuária na região Centro-Oeste.

\section{CONCLUSÕES}

O consórcio de sorgo granífero e braquiária na entrelinha, em safrinha, mostrou-se como técnica de cultivo viável para o sistema plantio direto visando produção de grãos, massa seca (palhada) e proteína bruta (forragem) na entressafra.

Para o rendimento de grãos, os consórcios do DKB 599 com as braquiárias na entrelinha não acarretaram reduções no rendimento de grãos em relação ao monocultivo do sorgo, exceto para a associação com a B. decumbens, semeada a $10 \mathrm{~cm}$ de profundidade, e B. ruziziensis, semeada a $2 \mathrm{~cm}$.

Em consórcio, a $B$. decumbens proporcionou maiores valores de cobertura do solo e relação $\mathrm{C} / \mathrm{N}$ da forragem.

\section{AGRADECIMENTOS}

Ao Conselho Nacional de Desenvolvimento Científico e Tecnológico (CNPq) pelo auxílio financeiro na realização do trabalho.

\section{REFERÊNCIAS}

Baumhardt RL, Tolk JA \&Winter SR (2005) Seeding practices and cultivar maturity effects on simulated dry land grain sorghum yield. Agronomy Journal, 97:935-942. 
Braz AJBP, Procópio SO, Cargnelutti Filho A, Silveira PM, Kliemann HJ, Cobucci T \& Braz GBP (2006) Emergência de plantas daninhas em lavouras de feijão e de trigo após o cultivo de espécies de cobertura de solo. Planta daninha, 24:621-628.

Calvo CL, Foloni JSS \& Brancalião SR (2010) Produtividade de fitomassa e relação $\mathrm{C} / \mathrm{N}$ de monocultivos e consórcios de guandu-anão, milheto e sorgo em três épocas de corte. Bragantia, 69:77-86.

Dan HA, Carrijo MS, Carneiro DF, Costa KAP \& Silva AG (2010) Desempenho de plantas sorgo granífero sobre condições de sombreamento. Acta Scientiarum, Agronomy, 32:675-679.

EMBRAPA Centro Nacional de Pesquisa de Solos (1997) Manual de métodos de análise de solo. $2^{\mathrm{a} e d}$. Rio de Janeiro, Embrapa/ CNPS. 212p.

Euclides VPB, Macedo MCM, Valle CB, Barbosa RA \& Gonçalves WV (2008) Produção de forragem e características da estrutura do dossel de cultivares de Brachiaria brizantha sob pastejo. Pesquisa Agropecuária Brasileira, 43:1805-1812.

Flores JPC, Anghinoni I, Cassol LC, Carvalho PCF, Leite JGDB \& Fraga TI (2007) Atributos físicos do solo e rendimento de soja em sistema plantio direto em integração lavoura-pecuária com diferentes pressões de pastejo. Revista Brasileira de Ciência do Solo, 31:771-780.

Heckler JC (2002) Sorgo e girassol no outono-inverno, em sistema plantio direto, no Mato Grosso do Sul, Brasil. Ciência Rural, 32:517-520.

Ikeda FS, MITJA D, Vilela L \& Carmona R (2007) Banco de sementes no solo em sistemas de cultivo lavoura-pastagem. Pesquisa Agropecuária Brasileira, 42:1545-1551.

Kliemann HJ, Braz AJPB \& Silveira PM (2006) Taxas de decomposição de resíduos de espécies de cobertura em latossolo vermelho distroférrico. Pesquisa Agropecuária Tropical, 36:2128.

Lanzanova ME, Nicoloso RS, Lovato T, Eltz FLF, Amado TJC \& Reinert DJ (2007) Atributos físicos do solo em sistema de integração lavoura-pecuária sob plantio direto. Revista Brasileira de Ciência do Solo, 31:1131-1140.

Machado LAZ \& Assis PGG (2010) Produção de palha e forragem por espécies anuais e perenes em sucessão à soja. Pesquisa Agropecuária Brasileira, 45:415-422.

Malavolta E, Vitti GC \& Oliveira SA (1997) Avaliação do estado nutricional de plantas: princípios e aplicações. $2^{\mathrm{a}}$ ed. Piracicaba, Potafos. 319p.

Matthew C, Assuero SG, Black CK \& Hamilton NRS (2000) Tiller dynamics of grazed swards. In: Lemaire G, Hodgson J, Moraes A, Carvalho PCF \& Nabinger C (Eds.) Grassland ecophysiology and grazing ecology. Wallingford, CABI Publishing.p.127-150.

Mello LMM, Yano ÉH, Narimatsu KCP, Takahashi CM \& Borghi É (2004) Integração agricultura-pecuária em plantio direto: produção de forragem e resíduo de palha após pastejo. Engenharia Agrícola, 24:121-129.
Menezes LAS \& Leandro WM (2004) Avaliação de espécies de coberturas do solo com potencial de uso em sistema de plantio direto. Pesquisa Agropecuária Tropical, 34:173-180.

Paciullo DSC, Aroeira LJM, Alvim MJ \& Carvalho MM (2003) Características produtivas e qualitativas de pastagem de braquiária em monocultivo e consorciada com estilosante. Pesquisa Agropecuária Brasileira, 38:421-426.

Pale S, Mason SC \& Galusha TD (2003) Planting time for early-season pearl millet and grain sorghum in Nebraska. Agronomy Journal, 95:1047-1053.

Portes TA, Carvalho SIC, Oliveira IP \& Kluthcouski J (2000) Análise do crescimento de uma cultivar de braquiária em cultivo solteiro e consorciado com cereais. Pesquisa Agropecuária Brasileira, 35:1349-1358.

Rezende PM, Silva AG, Botrel ÉP, Gomes LL \& Gris CF (2004) Consórcio Sorgo-Soja. VIII. Sistema de corte, cultivares de soja e híbridos de sorgo na produção de forragem das culturas consorciadas na entrelinha e monocultivo do sorgo. Revista Brasileira de Agrociência, 10:475-481.

Rodrigues RC, Mourão GB, Valinote AC \& Herling VR (2007) Reservas orgânicas, relação parte aérea-raiz e c-n e eliminação do meristema apical no capim-xaraés sob doses de nitrogênio e potássio. Ciência Animal Brasileira, 8:505-514.

Silva AG, Barros AS, Silva LHCP, Moraes EB, Pires R \& Teixeira IR (2009a) Avaliação de cultivares de sorgo granífero na safrinha no sudoeste do Estado de Goiás. Pesquisa Agropecuária Tropical, 39:168174.

Silva AG, Rezende PM, Gris CF, Gomes LL \& Botrel EP(2003) CONSÓRCIO SORGO-SOJA. IX. Influência de sistemas de cortes na produção de forragens de sorgo e soja consorciados na linha e de sorgo em monocultivo. Ciência e Agrotecnologia, 27:451-461.

Silva PCG, Foloni JSS, Fabris LB \& Tiritan CS (2009b) Fitomassa e relação $\mathrm{C} / \mathrm{N}$ em consórcios de sorgo e milho com espécies de cobertura. Pesquisa Agropecuária Brasileira, 44:1504-1512.

Silva MB, Kliemann HJ, Silveira PM \& Lanna AC (2007) Atributos biológicos do solo sob influência da cobertura vegetal e do sistema de manejo. Pesquisa Agropecuária Brasileira, 42:17551761 .

Souza CN, Souza IF \& Pasqual M (1999) Extração e ação do sorgoleone sobre o crescimento das plantas. Ciência e Agrotecnologia, 23:331-338.

Taiz L \& Zeiger E (2010) Plant physiology. 5aed. Sunderland, Sinauer Associates. 700p.

Timossi PC, Durigan JC \& Leite GJ (2007) Formação de palhada por braquiárias para adoção do sistema plantio direto. Bragantia, 66:617-622.

Torres JLR, Pereira MG, Andrioli I, Polidoro JC \& Fabian AJ (2005) Decomposição e liberação de nitrogênio de resíduos culturais de plantas de cobertura em um solo de cerrado. Revista Brasileira de Ciência do Solo, 29:609-618.

Vilela L, Soares WV, Sousa DMG \& Macedo MCM (1998) Calagem e adubação para pastagens na região do cerrado. Planaltina, EMBRAPA/CPAC. 16p. (Circular Técnica, 37). 